\title{
Language-Non-Selective Lexical Activation without Its Use for Sentential Interpretation: An Event-Related Potential (ERP) Study on the Processing of L1 Chinese and L2 Japanese Sentences
}

\author{
Katsuo Tamaoka1, Makoto Miyatani' ${ }^{2}$, Chao Zhang3, Maiko Shiraishi', Nao Yoshimura² \\ ${ }^{1}$ Graduate School of Languages and Cultures, Nagoya University, Nagoya, Japan \\ ${ }^{2}$ Graduate School of Education, Hiroshima University, Hiroshima, Japan \\ ${ }^{3}$ Shanghai Maritime University, Shanghai, China \\ ${ }^{4}$ Okinawa Women's Junior College, Okinawa, Japan \\ Email: ktamaoka@lang.nagoya-u.ac.jp
}

Received 24 March 2016; accepted 26 April 2016; published 29 April 2016

Copyright (C) 2016 by authors and Scientific Research Publishing Inc.

This work is licensed under the Creative Commons Attribution International License (CC BY). http://creativecommons.org/licenses/by/4.0/

(c) (i) Open Access

\section{Abstract}

An event-related potential (ERP) experiment was conducted to examine how native Chinese speakers with highly advanced Japanese language skills would process a sentence of a targeted language with no activation of an embedded word of an untargeted language. For the second language (L2) of Japanese in Experiment 1, three incorrect conditions were prepared for sentence correctness decisions: a Japanese sentence, including 1) a Chinese word (not existent in Japanese) semantically matched for the context, 2) a Chinese word (not existent in Japanese) semantically mismatched for the context, and 3) a nonword. For the first language (L1) of Chinese, sentences and target words were reversed (i.e., Chinese/Japanese respectively) for Experiment 2. The P200 peak appeared only for semantically mismatched L1 Chinese words embedded in L2 Japanese sentences compared to sentences containing a nonword. This P200 peak does not appear in the processing of L1 Chinese sentences compared to sentences containing a nonword. This result suggests extra attention to orthography is required at the early stage of processing. This reduces the activation of irrelevant information from the non-targeted language, in this case $\mathrm{L} 1$ Chinese. The $\mathbf{N 4 0 0}$ component was elicited in processing both $\mathrm{L} 2$ Japanese and L1 Chinese sentences with nonwords against L2 and L1 sentences with semantically matched and mismatched words of an untargeted language. These findings suggest that, regardless of whether there is a sentential semantic match in a targeted language, Chinese and Japanese bilinguals activate lexical concepts non-language-selectively. 
Although the nontargeted lexical concepts are non-selectively activated, they do not seem to be used for sentential interpretation for L2 Japanese and L1 Chinese.

\title{
Keywords
}

\author{
Language-Non-Selective, Language-Selective, Chinese-and-Japanese Bilinguals, ERP, N400, P200
}

\section{Introduction}

Two conflicting processing models have been presented for bilingual lexical access, a language-selective lexical access model and language-non-selective model. Language-selective access models (e.g., Gerard \& Scarborough, 1989; Rodriguez-Fornells, Rotte, Heinze, Nösselt, \& Münte, 2002) suggest that bilinguals can process the meaning of words in a targeted language with no activation from a non-targeted language. In contrast, languagenon-selective access models (e.g., Colomé, 2001; Costa, Caramazza, \& Sebastián-Gallés, 2000; de Groot, Delmaar, \& Lupker, 2000; Dijkstra \& van Heuven, 2002; Green, 1998; Hermans, Bongaerts, De Bot, \& Schreuder, 1998; Kroll \& Curley, 1988; van Heuven, Dijkstra, \& Grainger, 1998; van Heuven, Schriefers, Dijkstra, \& Hagoort, 2008) assume that lexical items with same semantics are tied to a single concept in the lexicon, and that these concepts can be activated by either language. A majority of studies contrasting these two processing models have been conducted in alphabetic languages.

Chinese and Japanese scripts share very similar morphemic units, known as hanzi characters in Chinese, or kanji characters in Japanese. Comparing Chinese and Japanese, only 36 of the 1945 basic kanji do not have an orthography correlate in the 3500 modern most commonly-used Chinese characters. In other words, 1909 kanji (98.2\%) are included in the core set of Chinese characters (Hishinuma, 1989). Chen (2002) counted 4600 Japanese kanji-compound words, and noted that $54.5 \%$ of those compounds can be written with same orthographic shape to denote the same meaning in Chinese. Furthermore, among the basic 2060 two-kanji compound words used in levels 4 to 2 of the Japanese proficiency test (Japan Foundation and Association of International Education, Japan, 2004), 1509 words (73.25\%) are orthographically and conceptually similar across Chinese and Japanese (Park, Xiong, \& Tamaoka, 2014; Xiong \& Tamaoka, 2014). A database of kanji compounds is available at http://kanjigodb.herokuapp.com; Yu and Tamaoka (2015) provide an explanation of how to use this website and search engine.

These Chinese characters and Japanese kanji share conceptually dense elements, so that the processing of compound words is likely to be highly dependent upon the conceptual lexicon attached to both Chinese and Japanese morphemic representations. Because of these orthographic similarities, Chinese and Japanese can be used to help differentiate between language-selective and language-non-selective models of processing. The present study further asked whether these concepts were used for sentential interpretation of the targeted language. In order to investigate language-selective or language-non-selective activation of lexical concepts, and their use for sentential interpretation of non-targeted language, the present study investigated whether or not Chinese-and-Japanese bilinguals activate a word of an untargeted language embedded in a sentence of the targeted language, and furthermore, whether a untargeted word would be activated for sentential interpretation of targeted language.

\section{Assumptions of Non-Language-Selective and Language-Selective Access in N400}

The present study focuses on conceptual activations of both Japanese and Chinese words in the sentential context. The negative 400 (N400) component in an ERP is a major concern. N400 is recognized as a reliable index of semantic context integration (e.g., Brown \& Hagoort, 1993; Friederici \& Kotz, 2003; Hahne \& Friederici, 2002; Hagoort, 2003; Kutas \& Federmeier, 2000; Kutas \& Hillyard, 1980), which appears when a word in a sentence does not make sense, as in "He drank tea with sugar and socks." The N400 is not observed when a sentence makes sense, as in "He drank tea with sugar and milk." (Kutas \& Hillyard, 1980). According to the language-selective lexical access model, bilinguals process a word from another untargeted language embedded in a sentence of the targeted language should be understood as a nonword. In such a case, the application of 
N400 should be observed. In contrary, if bilinguals use language-non-selective lexical access model, the untargeted, but semantically-matched word in the sentence of the target language should be understood as a real word, at least during the very early stage of sentence processing. This may elicit an N400. The semantically-matched lexical activation of untargeted language will stop eliciting N400 for sentence processing of the target language.

The present study contrasts three conditions exemplified as follows:

(1) A Chinese word (CH, not exist in Japanese) semantically-matched in a Japanese sentence

友達からのプレゼントは手表でした.

Tomodatyi-kara-no purezento-wa shoubiao $(\mathrm{CH})$ desita.

The present from my friend was a watch $(\mathrm{CH})$.

NP (my friend-from)-GEN NP (present)-TOP NP (watch, CH) V(be)-PAST.

(2) A Chinese word (CH, not exist in Japanese) semantically-mismatched in a Japanese sentence

友達からのプレゼントは公里でした.

Tomodatyi-kara-no purezento-wa gongli $(\mathrm{CH})$ desita.

The present from my friend was a kilometer $(\mathrm{CH})$.

NP (my friend-from)-GENNP (present)-TOP NP (kilometer CH) V(be)-PAST.

(3) A nonword (NW) in a Japanese sentence expecting the amplitude of N400

友達からのプレゼントは戸治でした。

Tomodatyi-kara-no purezento-wa huzhi (NW) desita.

The present from my friend was hushi (NW).

NP (my friend-from)-GENNP(present)-TOP NP (huzhi, NW) V(be)-PAST.

Instead of the proper Japanese two-kanji compound word for tokei “a watch" written as 時計 a Japanese, a Chinese equivalent word, shoubiao written 手表 (a watch), is inserted into sentence (1). Thus, the condition involves a Japanese sentence containing a semantically-matched Chinese word. Chinese-and-Japanese bilinguals should reject this sentence as incorrect because the Chinese word for a watch does not exist in Japanese. However, if they activate the Chinese word for "a watch" during the processing of Japanese sentence, this sentence must be understood as a correct sentence at the early stage, according to the language-non-selective lexical activation model. Then, the N400 component should not be elicited. Bilinguals will be able to recognize that this embedded word "watch" is Chinese at the later stage of sentential interpretation. Sentence (3) was created by inserting a nonword huzhi instead of tokei (a watch) in Japanese. This condition is the baseline, which we expectwill to produce the N400 component. Furthermore, sentence (2) was created by inserting a real Chinese word, 公理 meaning “a kilometer”, into the same sentence. Here, not only it does not exist in Japanese, but it is not matched with the semantics of the targeted Japanese sentence.

Based on these three sentence conditions, the following assumptions are made regarding bilingual lexical access and sentential interpretation under the two different models of language-selective and non-language-selective lexical activation. If Chinese-and-Japanese bilinguals can select only the targeted language (i.e., language-selective activation), the Chinese word for "a watch" as in sentence (1) would not be activated when processing the Japanese sentence. Likewise, the Chinese word gongli (a kilometer) in sentence (2) would be understood as containing a nonword. This results in the appearance of the N400 component as with the baseline sentence (3). In other words, if the N400 is observed under all the three conditions, (1) to (3), the language-selective model of the bilingual lexicon is supported.

On the contrary, Chinese-and-Japanese bilinguals could activate the Chinese word shoubiao (a watch) and appropriately integrate its meaning into the context of the Japanese sentence, understanding (1) as "the present from my friend was a watch.”, even though they are required to process the sentence in Japanese. In such a case, the amplitude of N400 will not appear in sentence (1). In other words, the baseline sentence (3) will elicit N400, but the condition in (1) will not. This contrasting result between sentences like (1) and (3) would supports a language-non-selective activation model. Yet, if sentence (2) does not elicit an N400, it could be interpreted that both Chinese words in sentences (1) and (2) would be language-non-selectively activated, but that these activated Chinese words would not be used for interpreting the sentential meaning of targeted sentence in Japanese. These assumptions were tested in Experiment 2 using an untargeted Chinese word in a targeted Japanese sentence as exemplified in sentences (1) to (3). Furthermore, the result of Experiment I would be confirmed by reversing the conditions for Experiment 2, using an untargeted Japanese word embedded in a targeted Chinese sentence. 


\section{Experiment 1-Processing Second Language (L2) Japanese Sentence}

\subsection{Method}

\subsubsection{Participants}

Ten Chinese students at the graduate level in Hiroshima University, Japan who are fluent in spoken and written Japanese (L1 Chinese and L2 Japanese bilinguals) participated in the experiments (6 females and 4 males). They were so fluent in Japanese that some of them might not be recognized as a L2 Japanese speaker by native Japanese speakers. Ages ranged from 24 years and 5 months to 29 years and 10 months, with the average age being 26 years 6 months, and a standard deviation of 1 year and 9 months on the day of the experiments.

\subsubsection{Materials of Experiment 1 (L2 Japanese)}

For the L2 Japanese speakers, as described in the previous section, the three incorrect conditions were created by placing a Chinese word in a Japanese sentence. These inserted Chinese words do not exist in Japanese, so they should be judged as incorrect words when the Japanese sentence is being processed. The three types of incorrect sentences (1)-(3) were experimental conditions, used for an analysis of ERPs. As shown in Table 1, a Chinese word 手表 meaning “a watch” is inserted in the Japanese sentence such as 友達からのプレゼントは手表で した. (The present from my friend was a watch.), where the order in which the three blocks were presented was

Table 1. A set of Japanese sentences used for the experiment.

\begin{tabular}{|c|c|c|}
\hline \multicolumn{3}{|c|}{ Three presentation blocks of sentences } \\
\hline 1st block & 2nd block & Target block \\
\hline \multicolumn{3}{|c|}{ 1. Correct “No” responses (incorrect sentences) } \\
\hline \multicolumn{3}{|c|}{ (1) Semantically matched Chinese words which do not exist in Japanese } \\
\hline 友達からの & プレゼントは & 手表でした。 \\
\hline tomodati-kara-no & purezento-wa & Shoubiao $(\mathrm{CH})$ desita. \\
\hline my friend-from-GEN & present-TOP & watch $(\mathrm{CH})$ be-PAST. \\
\hline \multicolumn{3}{|c|}{ (2) Semantically mismatched Chinese words which do not exist in Japanese } \\
\hline 友達からの & プレゼントは & 公里でした。 \\
\hline tomodati-kara-no & purezento-wa & gongli (CH) desita. \\
\hline my friend-from-GEN & present-TOP & kilo $(\mathrm{CH})$ be-PAST \\
\hline \multicolumn{3}{|c|}{ (3) Nonwords which do not exist either in Japanese or in Chinese } \\
\hline 友達からの & プレゼントは & 戸治でした. \\
\hline tomodati-kara-no & purezento-wa & huzhi (NW) desita. \\
\hline my friend-from-GEN & present-TOP & huzhi (NW) be-PAST. \\
\hline \multicolumn{3}{|c|}{ 2. Correct “Yes” responses (correct sentences) } \\
\hline 友達からの & プレゼントは & 万年筆でした. \\
\hline tomodati-kara-no & purezento-wa & man'nenhitu desita. \\
\hline my friend-from-GEN & present-TOP & pen be-PAST. \\
\hline 友達からの & プレゼントは & 時計でした。 \\
\hline tomodati-kara-no & purezento-wa & tokei desita. \\
\hline my friend-from-GEN & present-TOP & watch be-PAST. \\
\hline 友達からの & プレゼントは & かばんでした. \\
\hline tomodati-kara-no & purezento-wa & kaban desita. \\
\hline my friend-from-GEN & present-TOP & bag be-PAST. \\
\hline
\end{tabular}

Note: $\mathrm{CH}=$ Chinese words. NW = nonwords. TOP = topics. GEN = generative. CNs and NWs are described in pinyin. 
"from my friend", "the present" and the target block "was a watch”. In the head-final language of Japanese (the verb comes at the end of sentence), the target block including a Chinese word is always presented with a simple (or a light) verb. The Chinese word "a watch" fits semantically within the Japanese sentence context. However, this word does not exist in Japanese. Thus, this sentence must be rejected as an incorrect Japanese sentence.

The second condition used a similar context 友達からのプレゼントは公里でした. (The present from my friend was a kilometer.). Here, the targeted word does not only exist in Japanese (it is a Chinese word), it does not make semantic sense when used in this sentence (one cannot five "a kilometer"). Bilinguals could reject this sentence either because of the incongruence in semantic context or the target item's none existence in Japanese. The third condition includes a nonword in a sentence such as 友達からのプレゼントは戸治でした. (The present from my friend was huzhi). Fifty Japanese sentences with Chinese words were created for each condition of Experiment 1, resulting in 150 sentences. All sentences containing a Chinese word (or nonword) were considered to be incorrect. In addition, as shown in Table 1, an equal number of 150 correct sentences (containing all Japanese words) were prepared. A total of 300 sentences consisting of 150 incorrect and 150 Japanese correct sentences were used for Experiment 1.

\subsubsection{Stimulus Presentation}

Stimuli were presented to participants as follows: Sentences were presented in blocks of three. Incorrect sentences for "No" responses (Japanese sentences containing Chinese words) were shown to participants phrase-byphrase. The first Japanese phrase 友達からの tomodachi-kara-no "from my friend" was presented for 600 milliseconds (ms). After aninterval of $600 \mathrm{~ms}$, the second Japanese phase プレゼントは purezento-wa “a present” was also shown for $600 \mathrm{~ms}$. After another $600 \mathrm{~ms}$, the target verb phrase was presented in three different ways, first with Chinese words (1) “was a watch” 手表でした, (2) “was a kilometer” 公里でした and (3) “was a + [nonword]”戸治でした. After the target phrase in the third block was presented, ERPs were continuously measured for $800 \mathrm{~ms}$. The same presentation procedure was used for a correct "Yes" response (sentences only containing Japanese words). "No" and "Yes" responses were presented to each bilingual participant in a random order.

\subsubsection{ERP Measuring Instrument}

As shown in Figure 1, an electroencephalogram (EEG) was recorded from nineteen scalp electrodes corresponding to the International 10/20 system located in FP1, FP2, F7, F3, Fz, F4, F8, T7, C3, Cz, C4, T8, P7, P3, Pz, P4, P8, O1 and O2. These were amplified by a Nihon Kohden Digital EEG-1100 with a bandpass of 0.03 $30 \mathrm{~Hz}$. ERPs were sampled at a rate of $1000 \mathrm{~Hz}$ before $100 \mathrm{~ms}$ between the verb phrase presentation (third stimulus) onset to $800 \mathrm{~ms}$ after the presentation.

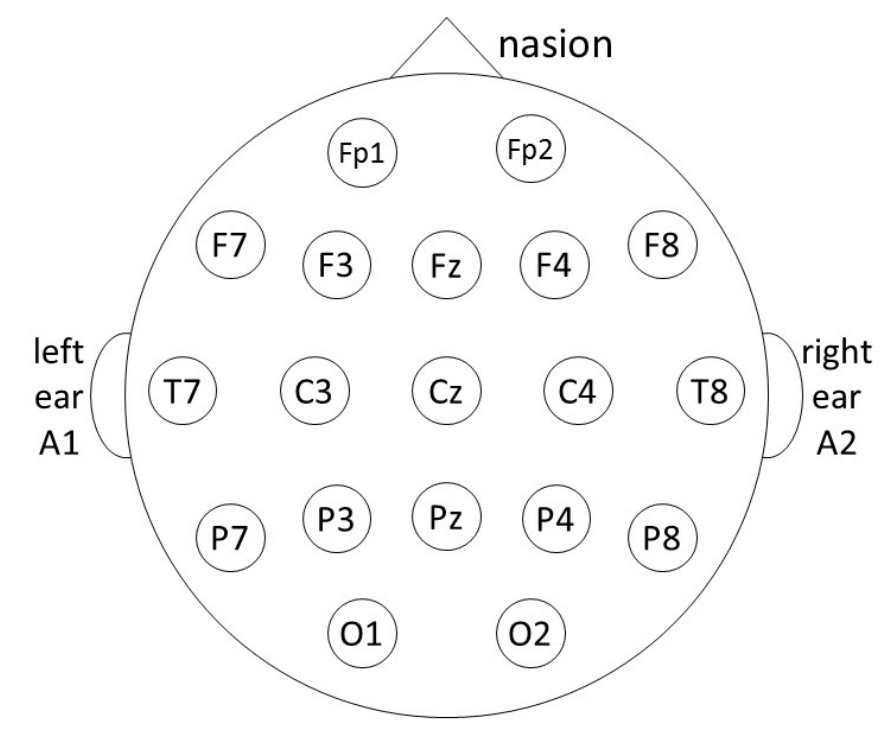

Figure 1. Schematic diagram of electrode montage used in the study. 


\subsection{Data Analysis and Results}

\subsubsection{ERP Data for the Processing of L2 Japanese Sentences}

Average ERP amplifications $(N=10)$ in four intervals of $180-240 \mathrm{~ms}, 320$ - $400 \mathrm{~ms}, 400$ - $480 \mathrm{~ms}$, and 550 $700 \mathrm{~ms}$ were analyzed by the same 3 (three incorrect stimulus conditions) $\times 19$ (locations) ANOVAs repeated measures. The ERPs in the $\mathrm{Cz}$ position are depicted in Figure 2. For the $180-240 \mathrm{~ms}$ interval, there was a significant main effect of incorrect stimulus conditions $[F(2,18)=6.95, p<.05]$. ERPs showed increasingly positive amplitudes in the order of semantically matched Chinese words, semantically mismatched Chinese words and nonwords, but multiple comparisons by the Ryan method showed a significant difference only between semantically matched Chinese words and nonwords. For the 320 - $400 \mathrm{~ms}$ interval, the main effect was significant in the incorrect stimulus condition $[F(2,18)=5.56, p<.05]$. Multiple comparisons revealed that nonwords were associated with greater negative amplitudes than the other two semantically matched and mismatched Chinese words conditions. There was no significant interaction. For the $400-480 \mathrm{~ms}$ interval, the main effect of the incorrect stimulus conditions was significant $[F(2,18)=13.28, p<.01]$. Multiple comparisons by the Ryan method showed that nonwords were associated with a greater negative amplitude than the other Chinese words conditions. The interaction was also significant $[F(36,324)=2.57, p<.05]$. With the exception of three locations of FP1, F7 and P7, all other locations showed significant main effects of incorrect stimulus conditions. Semantically mismatched Chinese words were associated with a greater negative amplitude than semanticallymatched Chinese words in $\mathrm{C} 3, \mathrm{Pz}, \mathrm{O} 1$ and O2. For the $550-700 \mathrm{~ms}$ interval, there was no significant main effect, but the interaction was significant $[F(36,324)=3.11, p<.05]$. In the five locations of FP2, Fz, F4, F8, and $\mathrm{Cz}$, nonwords were associated with a greater negative amplitude than both semantically matched and semantically mismatched Chinese word conditions, while no difference was detected between semantically matched and semantically mismatched Chinese word conditions.

\subsubsection{Discussion}

In the 180 - 240 interval, the P200 amplitude was observed in L2 Japanese sentence processing. Since the P200 was elicited during the processing of L2 Japanese sentence with a semantically mismatched Chinese word (semantically matched Chinese word also showed this tendency, but it was not significant), the P200 may imply extra orthographic attention at the early processing stage (Hackley, Woldorff, \& Hillyard, 1990; Liu, Perfetti, \& Hart, 2003; Luck \& Hillyard, 1994). Both Japanese sentences with semantically matched and semantically mismatched Chinese words did not amplify the N400. Chinese-and-Japanese bilinguals must activate lexical concepts from the non-target Chinese, even though they were processing Japanese (e.g., Brown \& Hagoort, 1993;

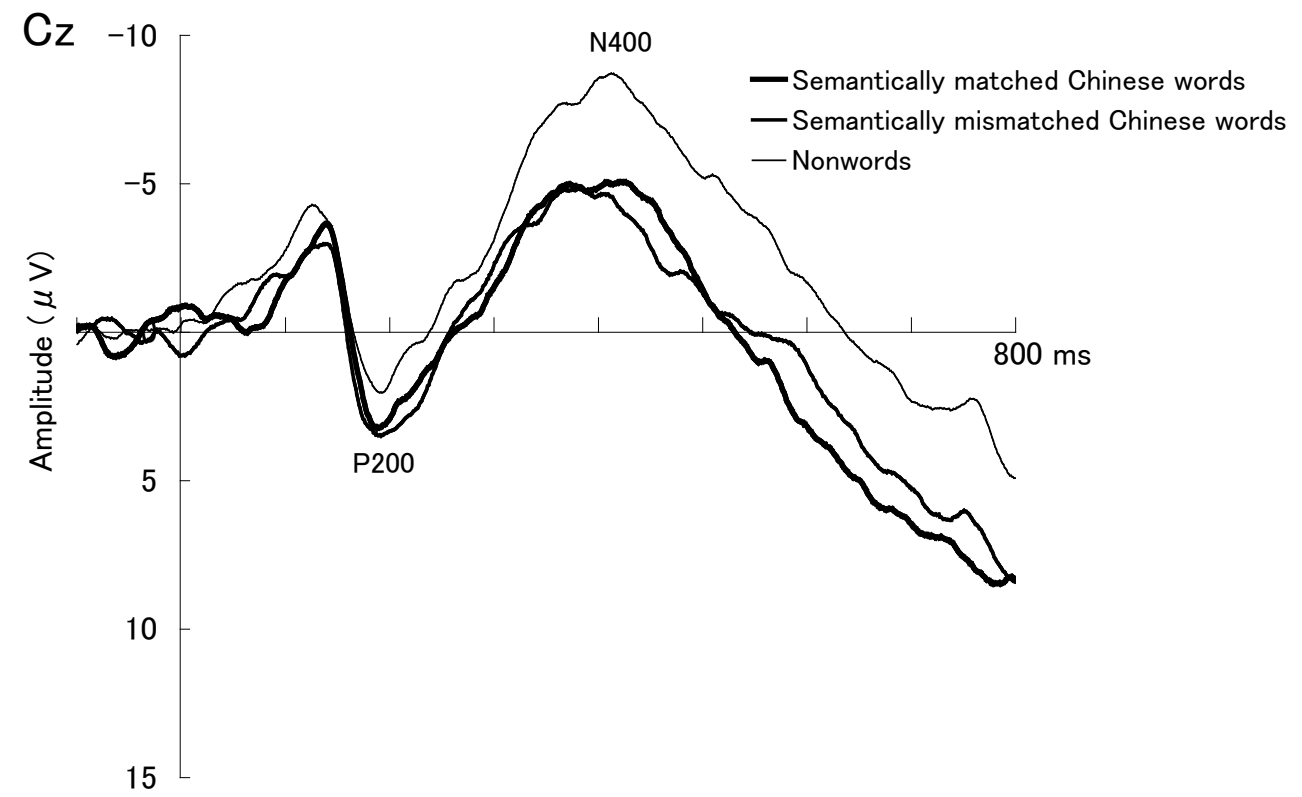

Figure 2. ERPs of Japanese sentences with Chinese words and nonwords. 
Friederici \& Kotz, 2003; Hahne \& Friederici, 2002; Hagoort, 2003; Kutas \& Federmeier, 2000; Kutas \& Hillyard, 1980). This result supports the model of non-language-selective activations of L1 and L2 lexical items (e.g., Brown \& Hagoort, 1993; Friederici \& Kotz, 2003; Hahne \& Friederici, 2002; Hagoort, 2003; Kutas \& Federmeier, 2000; Kutas \& Hillyard, 1980). However, the same tendency was observed both the semantically matched and semantically mismatched conditions. Therefore, although the fluent bilinguals cannot avoid lexical activations of their untargeted Chinese words, they do not seem to use these activated Chinese words for Japanese sentential interpretation.

\section{Experiment 2-Processing First Language (L1) Chinese Sentence}

\subsection{Method}

\subsubsection{Participants}

Participants were the same as Experiment 1.

\subsubsection{Materials of Experiment 2 (L1 Chinese)}

Stimulus items were reversed for Experiment 2, which used Chinese sentences containing a Japanese word, as shown in Table 2. The measurement of ERPs focused on decisions related to incorrectness. As shown in Table 2, three incorrect conditions were prepared for the sentence correctness decision task. A Chinese sentence including one of the following: (1) a semantically matched Japanese word, (2) a semantically mismatched Japanese word, or (3) a nonword.

\section{Table 2. A set of Chinese sentences used for the experiment.}

\begin{tabular}{|c|c|c|}
\hline \multicolumn{3}{|c|}{ Three presentation blocks of sentences } \\
\hline 1st block & 2nd block & Target block \\
\hline \multicolumn{3}{|c|}{ 1. Correct "No" responses (incorrect sentences) } \\
\hline \multicolumn{3}{|c|}{ (1) Semantically matched Japanese words which do not exist in Chinese } \\
\hline 这位是 & 我的 & 友达 \\
\hline zhe wei shi & wo de & tomodati (JP). \\
\hline this be & my & friend (JP). \\
\hline \multicolumn{3}{|c|}{ (2) Semantically mismatched Japanese words which do not exist in Chinese } \\
\hline 这位是 & 我的 & 风邪 \\
\hline zhe wei shi & wo de & kaze (JP). \\
\hline this be & my & cold (JP). \\
\hline \multicolumn{3}{|c|}{ (3) Nonwords which do not exist either in Japanese or in Chinese } \\
\hline 这位是 & 我的 & 中克 \\
\hline zhe wei shi & wo de & zhong ke (NW). \\
\hline this be & my & zhong ke (NW). \\
\hline \multicolumn{3}{|c|}{ 2. Correct “Yes" responses (correct sentences) } \\
\hline 这位是 & 我的 & 老师 \\
\hline zhe wei shi & wo de & lao shi. \\
\hline this be & my & teacher. \\
\hline 这位是 & 我的 & 同事 \\
\hline zhe wei shi & wo de & tong shi. \\
\hline this be & my & workmate \\
\hline 这位是 & 我的 & 父亲 \\
\hline zhe wei shi & wo de & fu qin. \\
\hline this be & my & father. \\
\hline
\end{tabular}

Note: JP = Japanese words. NW = nonwords. NWs are described in pinyin. 
For example, the first condition is a Chinese sentence such as, 这位是我的友达. (This is my friend.). Although the word "friend" fits semantically within the sentence context, it is a Japanese word. This word is represented in Chinese characters, but does not exist in Chinese. Thus, this sentence must be rejected as an incorrect Chinese sentence. The second condition also employ as similar context such as 这位是我的风邪. (This is my cold.). However, the word "cold" does not fit within the sentence context (one cannot show his/her "cold"). While this word exists in Japanese, it does not exist in Chinese. Bilinguals can reject this sentence because of either the none-existence of the word in Chinese or the semantic mismatch of the targeted word. The third condition includes a nonword in a sentence such as “这位是我的中克”. (This is my zhongke.). For correct sentence conditions, we used sets of three sentences such as “这位是我的老师”. (This is my teacher.). 这位是我的同事. (This is my workmate.), and “这位是我的父亲”. (This is my father.), all of which are correct Chinese sentences. Fifty sentences with Japanese words in each condition (a total of 150 sentences) were created for Experiment 2. These sentences were incorrect sentence which should be responded "No". In addition, as shown in Table 2, an equal number of 150 correct Chinese sentences were prepared. A total of 300 sentences consisting of 150 incorrect and 150 correct sentences were used for Experiment 2.

\subsubsection{Stimulus Presentation}

The stimulus presentation in Experiment 2 was the same as in Experiment 1.

\subsubsection{ERP Measuring Instrument}

The ERP Measuring Instrument in Experiment 2 was the same as in Experiment 1.

\subsection{Data Analysis and Results}

\subsubsection{ERP Data for the Processing of L2 Japanese Sentences}

Average ERP amplitudes $(N=10)$ for five intervals, 180 - $240 \mathrm{~ms}, 280$ - $360 \mathrm{~ms}, 360$ - $450 \mathrm{~ms}, 500$ - $640 \mathrm{~ms}$ and 640 - $800 \mathrm{~ms}$, were analyzed by 3 (three incorrect stimulus conditions) $\times 19$ (locations) ANOVAs repeated measures using Greenhouse-Geisser Epsilon to identify the significance level. There were no significant main effects or interaction in the 180 - $240 \mathrm{~ms}$ interval. For the 280 - $360 \mathrm{~ms}$ interval, the main effect was significant in the three different incorrect stimulus conditions $[F(2,18)=10.03, p<.01]$. Multiple comparisons by the Ryan method $(p<.05)$ revealed that nonwords were more negatively amplified than the two real Japanese words conditions. For the $360-450 \mathrm{~ms}$ interval, the main effect of verb phrase was significant $[F(2,18)=21.82, p<.0001]$. Multiple comparisons by the Ryan method showed that nonwords were more negatively amplified than the other two real Japanese word conditions. The interaction also approached a significant level $[F(36,324)=2.37, p<.07]$.

A clear picture of the ERPs in the Cz position in Figure 3 indicates the N400 component except in F7, P7 and

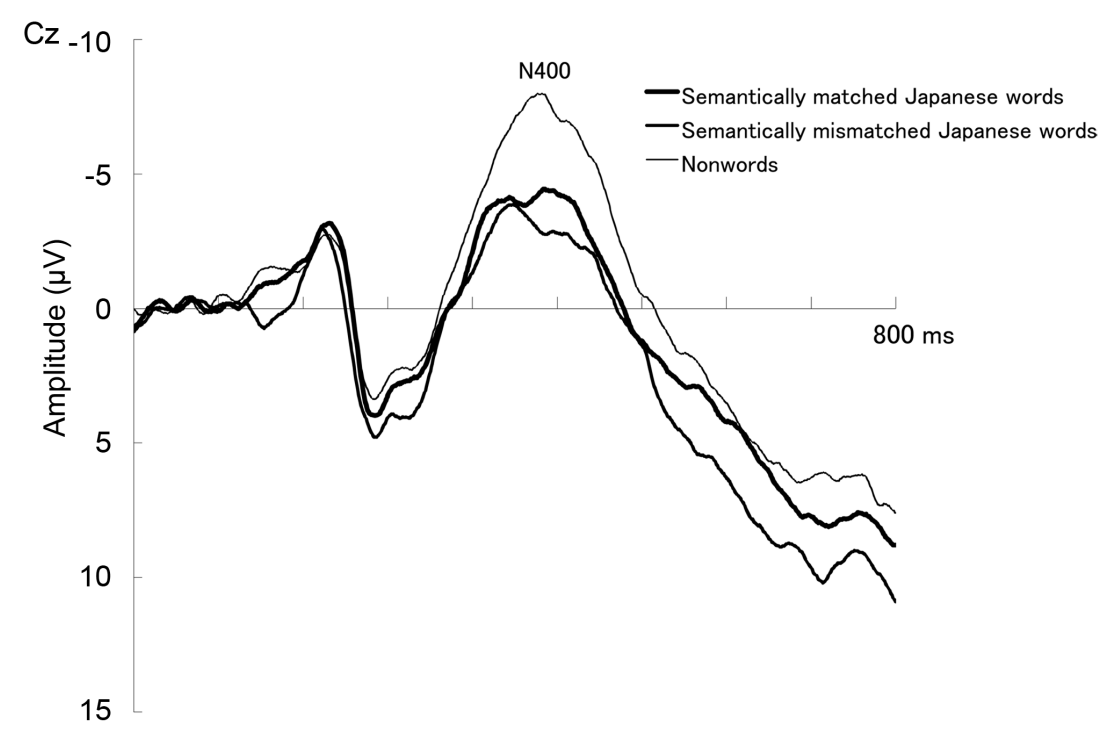

Figure 3. ERPs of Chinese sentences with Japanese words and nonwords. 
O1. For the 500 - $640 \mathrm{~ms}$ interval, the interaction was significant $[F(36,324)=3.72, p<.01]$. Significant main effects of incorrect stimulus conditions were found in the locations of PF1, PF2, Fz, F4, F8 and Cz. Semanticallymismatched Japanese words were more negatively amplified than matched Japanese words in the locations of FP1 and F8. For the 640 - 800 ms interval, there were no significant main effects or interactions.

\subsubsection{Discussion}

Unlike L2 Japanese sentence processing in Experiment 1, the P200 amplitude was not observed in L1 Chinese sentence processing in in the 180 - 240 interval. This might be related to the ease of early orthographic processing (Hackley, Woldorff, \& Hillyard, 1990; Liu, Perfetti, \& Hart, 2003; Luck \& Hillyard, 1994). As with Experiment 1, the N400 component was observed in the condition of nonwords in L1 Chinese sentence processing. Once again, both L1 Chinese sentence types with a semantically-matched and a semantically-mismatched Japanese word did not show the elicitation of N400 (e.g., Brown \& Hagoort, 1993; Friederici \& Kotz, 2003; Hahne \& Friederici, 2002; Hagoort, 2003; Kutas \& Federmeier, 2000; Kutas \& Hillyard, 1980). Therefore, lexical items of non-target language must be activated non-language-selectively under the sentence processing condition of either L1 or L2 (e.g., Colomé, 2001; Costa, Caramazza, \& Sebastián-Gallés, 2000; de Groot, Delmaar, \& Lupker, 2000; Dijkstra \& van Heuven, 2002; Green, 1998; Hermans, Bongaerts, De Bot, \& Schreuder, 1998; van Heuven, Dijkstra, \& Grainger, 1998; van Heuven, Schriefers, Dijkstra, \& Hagoort, 2008). However, these lexical activations do not involve sentential interpretation since the N400 was not found in Chinese sentences with either semantically-mismatch Japanese words or semantically-matched Japanese words.

\section{General Discussion}

In order to clarify whether a lexical concept from the untargeted language was activated while processing a sentence of the targeted language, the present study measured ERPs of highly advanced Chinese-and-Japanese bilinguals during the processing of L1 Chinese and L2 Japanese sentences. The two major amplitudes of P200 and N400 were observed in Experiments 1 and 2.

In the 180 - 240 interval, the P200 amplitude was observed in L2 Japanese sentence processing, but not in L1 Chinese sentence processing. A previous study by Hackley, Woldorff and Hillyard (1990) interpreted the P200 as reflecting selective attention. Similarly, Luck and Hillyard (1994) provided an explanation for the P200 as a visual feature detection processes. In a language related ERP study by Liu, Perfetti and Hart (2003), the P200 component was found in Chinese processing of graphically similar characters such as 零 and 雪, or 池 and 他. It seems that the P200 component reflects early orthographic activation before concepts are accessed. In the present study, the P200 was observed only in L2 Japanese sentence processing, but not in L1 Chinese sentence processing. This early P200 indicated the asymmetric performance between L1 Chinese and L2 Japanese. L2 Japanese words presented in Japanese script, kanji were embedded in L1 Chinese sentences. Japanese kanji characters resemble to the Chinese hanzi characters. In fact, previous experimental studies showed that L1 Chinese speakers learning L2 Japanese can process L2 Japanese kanji-compound words more quickly and accurately than other L2 learners with different language backgrounds (Tamaoka, 1997, 2000, 2014, 2015; Yamato \& Tamaoka, 2013). In the present study, L1 Chinese hanzi orthography was processed with a lower cognitive load than L2 Japanese even though L1 Chinese words in Japanese sentences were also presented in Japanese kanji characters. This finding provides further support for the asymmetric model of bilingual lexical access (e.g., Chen \& Leung, 1989; Chen \& Ng, 1989; Kroll \& Curley, 1994; Kroll \& Sholl, 1992; Kroll, Michael, Tokowicz, \& Dufour, 2002; Sholl, Sankaranarayanan, \& Kroll, 1995) which suggests the activation level of words from the dominant L1 (Chinese) is much stronger than that of words from the non-dominant L2 (Japanese).

The N400 component appears when semantic violations are processed in a sentence (e.g., Brown \& Hagoort, 1993; Friederici \& Kotz, 2003; Hahne \& Friederici, 2002; Hagoort, 2003; Kutas \& Federmeier, 2000; Kutas \& Hillyard, 1980), suggesting that the N400 is sensitive to conditions requiring semantic integration processes. In the present study, the N400 component was observed in the nonword condition in both L1 Chinese and L2 Japanese sentence processing. The N400 component appeared approximately 40 ms later in the L2 Japanese sentences, compared to L1 Chinese sentences. A delay of about $40 \mathrm{~ms}$ also observed between overall "Yes" responses in L1 Chinese and L2 Japanese processing. Previous studies (Ardal, Donald, Meuter, Muldrew, \& Luce, 1990; Hahne, 2001; Ojima, Nakata, \& Kakigi, 2005) have also shown that semantic anomalies often elicit slight delays in the non-dominant L2 language. 
The semantically matched conditions did not amplify the N400. That the N400 did not appear suggests that bilinguals activate lexical concepts from the untargeted language even though they were processing targeted language. Therefore, the Chinese and Japanese fluent bilinguals cannot avoid conceptual activations of their L1 Chinese and L2 Japanese lexical items. Non-language-selection lexical activation (e.g., Colomé, 2001; Costa, Caramazza, \& Sebastián-Gallés, 2000; de Groot, Delmaar, \& Lupker, 2000; Dijkstra \& van Heuven, 2002; Green, 1998; Hermans, Bongaerts, De Bot, \& Schreuder, 1998; van Heuven, Dijkstra, \& Grainger, 1998; van Heuven, Schriefers, Dijkstra, \& Hagoort, 2008) was supported by the N400 patterns in the present study.

However, in the present study, both L1 and L2 sentences with semantically mismatched words of untargeted languages did not elicit an N400. In other words, a sentence context of the targeted language was not influenced by activation of words from the untargeted language. Therefore, bilinguals seem not to use these activated untargeted words for sentential interpretation of the target language. Since this tendency was observed in the both L1 and L2 processing condition, it is quite possible to have the cut-off mechanism of lexical activation in the untargeted language from sentence processing of the targeted language. This cut-off mechanism should be investigated in future studies on bilingual sentence processing.

\section{Acknowledgements}

The present work was supported by a Grant-in-Aid for Challenging Exploratory Research from the Japan Society of the Promotion of Science (JSPS) Grant Number 25580112 (principal researcher: Katsuo Tamaoka) and by a Grant-in-Aid for Grant-in-Aid for Scientific Research (C) from JSPS Grant Number 15K02656 (principal researcher: Kazuko Komori).

\section{References}

Ardal, S., Donald, M. W., Meuter, R. Muldrew, S., \& Luce, M. (1990). Brain Responses to Semantic Incongruity in Bilinguals. Brain and Language, 39, 187-205. http://dx.doi.org/10.1016/0093-934X(90)90011-5

Brown, C., \& Hagoort, P. (1993). The Processing Nature of the N400: Evidence from Masked Priming. Journal of Cognitive Neuroscience, 5, 34-44. http://dx.doi.org/10.1162/jocn.1993.5.1.34

Chen, H.-C., \& Ng, M.-L. (1989). Semantic Facilitation and Translation Priming Effects in Chinese-English Bilinguals. Memory \& Cognition, 17, 454-462. http://dx.doi.org/10.3758/BF03202618

Chen, H-C., \& Leung, Y-S. (1989). Patterns of Lexical Processing in a Nonnative Language. Journal of Experimental Psychology: Learning, Memory, and Cognition, 15, 316-325. http://dx.doi.org/10.1037/0278-7393.15.2.316

Chen, Y.-M. (2002). Nihon-go niji kanji goi to sore-ni taioo suru chuugokugo niji kanji goi-wa onaji ka-Taiwan oyobi chuugoku-no chuugokugo tono hikaku [Are Two-Kanji Compounds in Japanese the Same as Those in Chinese-A Comparison of the Chinese Language in Taiwan and the Mainland China]. Gengo Bunka to Nihongo Kyooiku [Language Culture and Japanese Education], 24, 40-53. (In Japanese)

Colomé, A. (2001). Lexical Activation in Bilinguals’ Speech Production: Language-Specific or Language Independent? Journal of Memory and Language, 45, 721-736. http://dx.doi.org/10.1006/jmla.2001.2793

Costa, A., Caramazza, A., \& Sebastián-Gallés, N. (2000). The Cognate Facilitation Effect: Implications for Models of Lexical Access. Journal of Experimental Psychology: Learning, Memory, and Cognition, 26, 1283-1296. http://dx.doi.org/10.1037/0278-7393.26.5.1283

de Groot, A. M. B., Delmaar, P., \& Lupker, S. J. (2000). The Processing of Interlexical Homographs in Translation Recognition and Lexical Decision: Support for Non-Selective Access to Bilingual Memory. Quarterly Journal of Experimental Psychology, 53A, 397-428. http://dx.doi.org/10.1080/713755891

Dijkstra, T., \& van Heuven, W. J. B. (2002). The Architecture of the Bilingual Word Recognition System: From Identification to Decision. Bilingualism: Language and Cognition, 5, 175-197. http://dx.doi.org/10.1017/s1366728902003012

Friederici, A. D., \& Kotz, S. A. (2003). The Brain Basis of Syntactic Processes: Functional Imaging and Lesion Studies. NeuroImage, 20, 8-17. http://dx.doi.org/10.1016/j.neuroimage.2003.09.003

Gerard, L. D., \& Scarborough, D. L. (1989). Language-Specific Lexical Access of Homographs by Bilinguals. Journal of Experimental Psychology: Learning, Memory, and Cognition, 15, 305-315. http://dx.doi.org/10.1037/0278-7393.15.2.305

Green, D. W. (1998). Mental Control of the Bilingual Lexico-Semantic System. Bilingualism: Language and Cognition, 1, 67-81. http://dx.doi.org/10.1017/S1366728998000133

Hackley, S. A., Woldorff, M., \& Hillyard, S. A. (1990). Cross-Modal Selective Attention Effects on Retinal, Myogenic, Brainstem, and Cerebral Evoked Potentials. Psychophysiology, 27, 195-208. 
http://dx.doi.org/10.1111/j.1469-8986.1990.tb00370.x

Hagoort, P. (2003). Interplay between Syntax and Semantics during Sentence Comprehension: ERP Effects of Combining Syntactic and Semantic Violations. Journal of Cognitive Neuroscience, 15, 883-899. http://dx.doi.org/10.1162/089892903322370807

Hahne, A. (2001). What's Difference in Second-Language Processing? Evidence from Event-Related Potentials. Journal of Psycholinguistic Research, 30, 251-265. http://dx.doi.org/10.1023/A:1010490917575

Hahne, A., \& Friederici, A. D. (2002). Differential Task Effects on Semantic and Syntactic Processes as Revealed by ERPs. Cognitive Brain Research, 13, 339-356. http://dx.doi.org/10.1016/S0926-6410(01)00127-6

Hermans, D., Bongaerts, T., De Bot, K., \& Schreuder, R. (1998). Producing Words in a Foreign Language: Can Speakers Prevent Interference from Their First Language? Bilingualism: Language and Cognition, 1, 213-229. http://dx.doi.org/10.1017/S1366728998000364

Hishinuma, T. (1989). Chuugoku-go no kantai-ji to jooyoo kanji [Simplified Chinese Characters and Commonly-Used Japanese Kanji]. In K. Sato (Ed.), Kanji kooza [A Lecture Series on Kanji] (pp. 258-276). Tokyo: Meiji Shoten.

Japan Foundation and Association of International Education, Japan (2004). Nihongo Nooryoku Shiken Shutsudai Kijun (Kaitei-ban) [Japanese Language Proficiency Test: Test Content Specifications] (2nd Print). Tokyo: Bonjinsha. (In Japanese)

Kroll, J. F., \& Curley, J. (1988). Lexical Memory in Novice Bilinguals: The Role of Concepts in Retrieving Second Language Words. In M. Gruneberg, P. Morris, \& R. Sykes (Eds.), Practical Aspects of Memory (Vol. 2, pp. 389-395). London: John Wiley \& Sons.

Kroll, J. F., \& Sholl, A. (1992). Lexical and Conceptual Memory in Fluent and Nonfluent Bilinguals. In R. Harris (Ed.), Cognitive Processing in Bilinguals (pp. 191-204). Amsterdam: Elsevier.

http://dx.doi.org/10.1016/S0166-4115(08)61495-8

Kroll, J. F., \& Stewart, E. (1994). Category Interference in Translation and Picture Naming: Evidence for Asymmetric Connections between Bilingual Memory Representations. Journal of Memory and Language, 33, 149-174. http://dx.doi.org/10.1006/jmla.1994.1008

Kroll, J. F., Michael, E., Tokowicz, N., \& Dufour, R. (2002). The Development of Lexical Fluency in a Second Language. Second Language Research, 18, 137-171. http://dx.doi.org/10.1191/0267658302sr201oa

Kutas, M., \& Federmeier, K. D. (2000). Electrophysiology Reveals Semantic Memory Use in Language Comprehension. Trends in Cognitive Sciences, 4, 463-470. http://dx.doi.org/10.1016/S1364-6613(00)01560-6

Kutas, M., \& Hillyard, S. A. (1980). Reading Senseless Sentences: Brain Potentials Reflect Semantic Anomaly. Science, 207, 203-205. http://dx.doi.org/10.1126/science.7350657

Liu, Y., Perfetti, C. A., \& Hart, L. (2003). ERP Evidence for the Time Course of Graphic, Phonological and Semantic Information in Chinese Meaning and Pronunciation Decisions. Journal of Experimental Psychology: Learning, Memory, and Cognition, 29, 1231-1247. http://dx.doi.org/10.1037/0278-7393.29.6.1231

Luck, S. J., \& Hillyard, S. A. (1994). Electrophysiological Correlates of Feature Analysis during Visual Search. Psychophysiology, 31, 297-308. http://dx.doi.org/10.1111/j.1469-8986.1994.tb02218.x

Ojima, S., Nakata, H., \& Kakigi, R. (2005). An ERP study of second language learning after childhood: Effects of proficiency. Journal of Cognitive Neuroscience, 17, 1212-1228. http://dx.doi.org/10.1162/0898929055002436

Park, S., Xiong, K. \& Tamaoka, K. (2014). Dookei niji kanjigo-no hinshisei-ni kansuru nikkanchuu data baasu [A Database of Grammatical Categories for Orthographically-Similar Two-Kanji Compound Words among Japanese, Korean and Chinese]. Kotoba-no Kagaku (Studia Linguistica), 27, 53-111. (In Japanese)

Rodriguez-Fornells, A., Rotte, M., Heinze, H-J., Nösselt, T., \& Münte, T. F. (2002). Brain Potential and Functional MRI Evidence for How to Handle Two Languages with One Brain. Nature, 415, 1026-1029. http://dx.doi.org/10.1038/4151026a

Sholl, A., Sankaranarayanan, A., \& Kroll, J. F. (1995). Transfer between Picture Naming and Translation: A Test of Asymmetries in Bilingual Memory. Psychological Science, 6, 45-49. http://dx.doi.org/10.1111/j.1467-9280.1995.tb00303.x

Tamaoka, K. (1997). Chuugokugo to eigo-o bogo tosuru nihongo gakushuusha-no kanji oyobi kanashori hooryaku [Processing Strategies of Words Presented in Kanji and Kana by Chinese and English Speakers Learning Japanese]. Gengo Bunka Kenkyuu [Studies in Language and Literature] (Matsuyama University), 17, 65-77. (In Japanese)

Tamaoka, K. (2000). Chuugokugo oyobi eigo-kei nihongo gakushuusha-no bogo-no hyooki keitai-ga nihongo-no on'inshorini oyobosu eikyoo [The Effects of Mother-Tongue Scripts on the Phonological Processing of the Japanese Language by Chinese and English Speakers]. Dokusho Kagaku [The Science of Reading], 44, 83-94. (In Japanese)

Tamaoka, K. (2014). The Japanese Writing System and Lexical Understanding. Japanese Language and Literature (The American Association of Teachers of Japanese, AATJ), 48, 431-471. 
Tamaoka, K. (2015). Chapter 18: Processing of the Japanese Language by Native Chinese Speakers. In M. Nakayama (Ed.), Handbooks of Japanese Psycholinguistics (pp. 283-332), Berlin: De Gruyter Mouton. http://dx.doi.org/10.1515/9781614511212-025

van Heuven, W. J. B., Dijkstra, T., \& Grainger, J. (1998). Orthographic Neighborhood Effects in Bilingual Word Recognition. Journal of Memory and Language, 39, 458-483. http://dx.doi.org/10.1006/jmla.1998.2584

van Heuven, W. J. B., Schriefers, H., Dijkstra, T., \& Hagoort, P. (2008). Language Conflict in the Bilingual Brain. Cerebral Cortex, 18, 2706-2716. http://dx.doi.org/10.1093/cercor/bhn030

Xiong, K., \& Tamaoka, K. (2014). Nittuu dookei niji kanjigo-no hinshisei-no taioo kankei-ni kansuru koosatsu [A Descriptive Analysis of Japanese-and-Chinese Orthographically-Similar Two-Kanji Compound Words According to the Database of Grammatical Categories]. Kotoba-no Kagaku (Studia Linguistica), 27, 25-51. (In Japanese)

Yamato, Y., \& Tamaoka, K. (2013). Chuugokugo bogo washa to kankokugo bogo washa-no nihongo tekisuto-no yomi shori-ni okeru bogo tono gengo teki ruijisei-no eikyoo [Effects of Linguistic Similarity on Japanese Text Processing by Native Chinese and Korean Speakers]. Koide kinen nihongo kyooiku kenkyuu-kai ronbun-shuu [Koide-Memorial Journal of Japanese Language Education], 21, 229-268. (In Japanese)

Yu, S., \& Tamaoka, K. (2015). Nikkanchuu dookei niji kanjigo-no hinshisei web-kensaku engin [A Web-Accessible Search Engine for Grammatical Category of Orthographically-Similar Two-Kanji Compound Words between Japanese, Korean and Chinese]. Kotoba-no Kagaku (Studia Linguistica), 28, 43-61. (In Japanese) 